\title{
Evaluation of Genetic Diversity of Cis-acting Elements of Abscisic Acid Responsive Element Binding Protein $(A B R E-B P)$ in Selected Sri Lankan Rice varieties
}

\author{
W.M.A. Senavirathne, D.V. Jayatilake ${ }^{1}$, V. Herath ${ }^{1 *}$ and H.A.M.Wickramasinghe ${ }^{1}$ \\ Postgraduate Institute of Agriculture \\ University of Peradeniya \\ Sri Lanka
}

\begin{abstract}
Salinity is a major abiotic stress that affects rice cultivation. Osmotic stress caused by salinity activates tolerance mechanisms in rice. The Abscisic Acid Responsive Element Binding Protein (ABRE-BP), transcribes for a bZIP family transcription factor that binds to the cis-regulatory element Abscisic Acid Responsive Element (ABRE) at the promoter of downstream salinity responsive genes and regulates their expression. Hence, the study was focused on analyzing the nucleotide diversity of a region in ABRE-BP promoter. Analysis of the ABRE-BP sequences of 47 Sri Lankan rice varieties and two reference varieties retrieved from a public database revealed many insertions and deletions (INDELs) and single nucleotide polymorphisms (SNPS) in the promoter. Eleven, abiotic stress related cis-elements were identified, but none of the INDELs spanned over them. However, SNPs either deleted existing cis-elements or created new cis-elements. The salinity stress responsive elements, MYBCORE and GTIGMSCAM4 were detected in few varieties, and were not associated with salinity tolerance based on current available salinity ratings. The presence of SNPs in cis-elements clustered them to nine groups at $68 \%$ similarity. The DNA polymorphisms on stress responsive cis-acting elements did not show a strong association with the known salinity ratings of many varieties. Nevertheless, the presence of INDELs affects the relative distance between elements, and thus may alter the expression of the $A B R E-B P$ that regulates downstream stress responsive genes.
\end{abstract}

Keywords: ABRE-BP, ABRE, Cis- elements, Salinity, Sri Lankan rice varieties

\section{INTRODUCTION}

Rice (Oryza sativa L.) is cultivated in regions with diverse environmental conditions. In some parts of the world, rice is grown under various abiotic stress conditions such as: drought, submergence, frost prone conditions, saline, acidic and toxic soils (Sankar et al., 2011). These conditions directly affect the plant growth and its productivity. Out of the persisting abiotic stress factors, drought and salinity are the major contributors to crop failure in rice cultivations (Bartels and Sunkar, 2005). Due to the climatic changes, rising of sea levels, geo-chemical weathering of rocks and improper drainage in cultivated lands, rapid expansion of salinity affected land is expected (El-Swaify, 2000). It is hard to treat and amend a salinity affected soil and thus, only the crops that are tolerant to such adverse conditions can be cultivated (Pitman and Lauchli, 2002). Due to the fact that $20 \%$ of irrigated

\footnotetext{
1 Department of Agricultural Biology, Faulty of Agriculture, University of Peradeniya, Sri Lanka

* Author for correspondence: venurah@pdn.ac.lk
} 
lands under cultivation are affected by soil salinity, development of rice cultivars that are tolerant to salinity is a priority in rice breeding programs all over the world (Pitman and Lauchli, 2002).

When a plant is under stress, the stress signal gets transmitted to responsive sites via many pathways including regulation of ion homeostasis via salt overly sensitive (SOS) regulatory pathway for ions and hormones induce signal transduction pathways such as abscisic acid (ABA)-dependent pathway (Sairam and Tyagi, 2004). Increasing soil salinity changes the osmotic potential of the plant cell and creates a water deficit condition, a potential stressful condition triggering the activation of salinity tolerance response gene cascades (Shinozaki and Yamaguchi-Shinozaki, 1997).The activation of the synthesis of the plant stress hormone $\mathrm{ABA}$, in turn activates a cascade of stress responsive genes to deliver plant tolerance/resistance responses (Nakashima et al., 2009). The ABA inducible stress responsive genes such as, salt, GST and $\mathrm{rab}$ 16-A delivering salinity tolerance have been reported in rice (Mundy and Chua, 1988; Garcia et al., 1998; Taji et al., 2002; Rabbani et al., 2003; Walia et al., 2005; Jain et al., 2010).

The $a b$ scisic acid responsive element (ABRE) is a commonly found cis-element in stress responsive genes (Uno et al., 2000). A bZIP-family transcription factor $A B R E-B P$ binds to the ABRE cis-element(s) and induces the expression of ABA-inducible salinity responsive genes in rice (Nakashima et al., 2009; Todaka et al., 2015). Thus, the expression of the salinity responsive genes in $A B R E-B P$ regulon is dependent upon the level of expression of the $A B R E-B P$. The $c i s$-elements found in the promoter of $A B R E-B P$ and the distance between those elements are crucial in mediating its expression. To our knowledge, the $A B R E-B P$ promoter region of different rice varieties has not been characterized. Identifying and comparing the cis-elements, their relative distance and DNA polymorphisms may shed insight on the contribution of these elements for the salinity responses in these varieties. The salinity responses of most Sri Lankan varieties are not well characterized and of those that have been characterized the actual salinity ratings reported in previous work have been at times contradictory (de Costa et al., 2012; Pradheeban et al., 2014). However, varieties such as Pokkali and Kuruluthudu are well known for their salinity tolerance.

In the current in silico analysis, sequences covering the upstream region of $A B R E-B P$ of 47 Sri Lankan rice varieties and two reference varieties (cultivar 93-11(indica) and Nipponbare (japonica)) were used to detect DNA polymorphisms of the $A B R E-B P$ promoter region, specially at $c i s$-elements related to abiotic stresses and their possible contribution to salinity responses.

\section{METHODOLOGY}

\section{DNA resources}

For the current study, a $800 \mathrm{bp}$ sequence upstream of the transcription start site (TSS) in $A B R E-B P$, of 47 Sri Lankan rice varieties were retrieved from the Rice SNP-Seek Database (http://oryzasnp.org/iric-portal/) using the locus position of $A B R E-B P$ in $O$. sativa subsp. japonica (OS06G0211200; chromosome 6 position 5,676,157 to 5,682,033) (Table 1). Sequences of reference varieties $O$. sativa subsp. japonica cv. Nipponbare (Os06g0211200) and $O$. sativa subsp. indica cv. 93-11 (BGIOSGA022536) were retrieved from the Gramene database (http://www.gramene.org/). 
Table 1. Selected Sri Lankan rice varieties and their accession numbers

\begin{tabular}{|c|c|}
\hline Rice Variety & Accession Number \\
\hline 105 & IRGC 40896-1 \\
\hline 3210 & IRGC 116950-1 \\
\hline A $69-1$ & IRGC 55305-1 \\
\hline Alagusamba & IRGC 8944-2 \\
\hline Balasuriya & IRGC 66509-1 \\
\hline BW 295-5 & IRGC 63098-1 \\
\hline Chandina & IRGC 36420-1 \\
\hline GalawakaHanderan & IRGC 31381-1 \\
\hline Godawel & IRGC 15750-1 \\
\hline H 6 & IRGC 157-1 \\
\hline HalsuduHeenati & IRGC 15599-1 \\
\hline Heendikwee & IRGC 15587-2 \\
\hline Herath Banda & IRGC 67630-1 \\
\hline Hodarawala & IRGC 67631-1 \\
\hline Honderawala & IRGC 47372-1 \\
\hline Kahatawee & IRGC 12004-1 \\
\hline KaluIlankalayan & IRGC $36270-1$ \\
\hline KaruthaSeenati & IRGC $15515-2$ \\
\hline Kotteyaran & IRGC 47383-1 \\
\hline Kula Karuppan & IRGC 55328-1 \\
\hline Kurukaruppan & IRGC 15449-1 \\
\hline Kurulu Wee (white) & IRGC 66518-1 \\
\hline Kurulutudu & IRGC 36304-1 \\
\hline Matholuwa & IRGC 8901-1 \\
\hline ModdaiKaruppan & IRGC 15465-1 \\
\hline Mudaliga Wee & IRGC 74706-1 \\
\hline Murunga & IRGC 15428-1 \\
\hline Muttu Samba & IRGC 36333-1 \\
\hline NalumoolaiKaruppan & IRGC 8993-1 \\
\hline Pachchaperumal & IRGC 3474-1 \\
\hline Pannithi & IRGC 51049-1 \\
\hline PeriyaVellai & IRGC $15475-1$ \\
\hline PodiHeenati & IRGC 36345-1 \\
\hline Podiwee & IRGC 11938-1 \\
\hline Pokkali & IRGC 8948-1 \\
\hline PuttuNellu & IRGC 55346-1 \\
\hline Race Perumal & IRGC 55347-1 \\
\hline Rangoon Samba & IRGC 11940-1 \\
\hline Ranruwan & IRGC 36360-1 \\
\hline Samba & IRGC 11993-1 \\
\hline Sayam & IRGC 31538-2 \\
\hline Sigardis & IRGC $15555-1$ \\
\hline SinnaSitira Kali & IRGC 51064-1 \\
\hline SithaiyanKottai Samba & IRGC 50155-1 \\
\hline SuduKarayal & IRGC 15348-1 \\
\hline VellaiKolomban & IRGC $15517-1$ \\
\hline WIR 1391 & IRGC 51605-1 \\
\hline
\end{tabular}




\section{Sequence analysis}

The retrieved $A B R E-B P$ promoter sequences of 47 Sri Lankan varieties and two reference varieties, were aligned using ClustalW (cost matrix: IUB, gap open cost: 15 and gap extend cost: 6.66) in Geneious v7.1.3 (Biomatters Ltd., New Zealand) with manual editing. The nucleotide polymorphisms of the promoter region were analyzed using DnaSP v5.10.1 (University of Bacelona, Spain). The cis-elements present in the promoter of the ABRE-BP were identified and was annotated using the PLACE database (https://sogo.dna.affrc.go.jp; Higo et al., 1999). A cluster analysis (complete linkage method and euclidean distance) was carried out considering the single nucleotide polymorphisms (SNPs) present within the identified cis-elements, using Minitab v15 (Minitab Inc., USA).

\section{RESULTS}

The retrieved 800 bp promoter regions of the $A B R E-B P$ sequences, revealed six INDELs at the positions, $787 \mathrm{bp}$ (INDEL 1), $757 \mathrm{bp}$ (INDEL 2), $696 \mathrm{bp}$ (INDEL 3), $695 \mathrm{bp}$ (INDEL 4), $572 \mathrm{bp}$ (INDEL 5) and $336 \mathrm{bp}$ (INDEL 6) upstream of the TSS (Fig. 1). The INDEL 1 with a 25 bp region was the longest INDEL. The varieties Puttunellu and cultivar 93-11 lacked sequence at INDEL1. The sequence spanning INDEL 2, INDEL 3, and INDEL 5 was rare among the selected varieties (of the varieties, 93\% (INDEL 2), 73\% (INDEL 3), and 36\% (INDEL 5), did not consist sequences spanning the given INDELs). Further, the sequences spanning INDEL1, INDEL4 and INDEL6 were often present. Out of the varietal panel 4\% did not consist sequences spanning over the INDEL 1, 4\% spanning the over INDEL 4, and $16 \%$ spanning over the INDEL 6 , respectively.

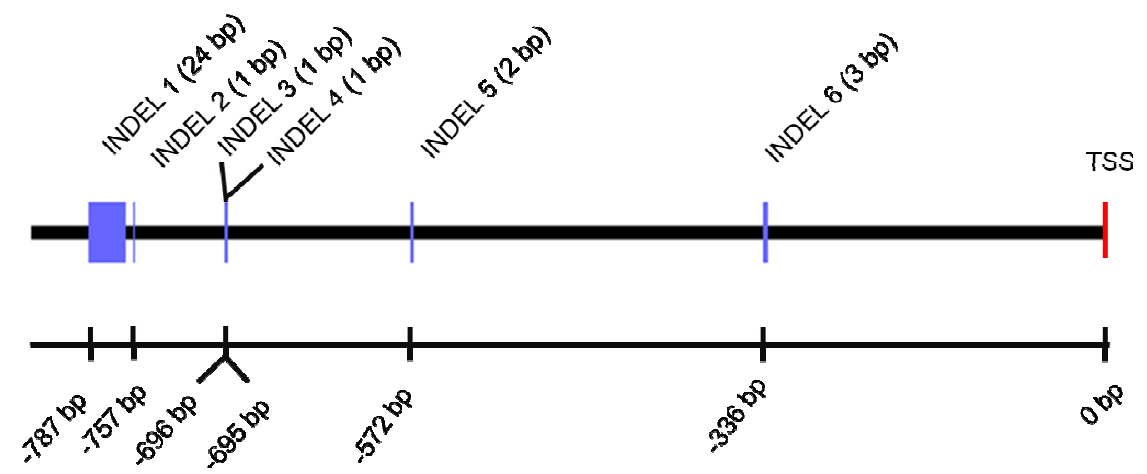

Fig. 1. Illustration of the size and the positions of six insertions/deletions (INDEL) starting from the transcription start site (TSS) in the promoter region of abscisic acid responsive element binding protein

The in silico analysis revealed presence of 57 SNP sites among the 49 varieties (data not shown). The frequency of occurrence of all SNP sites in the considered region was $7.4 \%$. Out of that, $6.6 \%$ (51 SNPs) were parsimony informative sites and $0.8 \%$ (six SNPs) were singleton variables. Out of the 51 parsimony informative sites, 42 sites lead to transition mutations and nine to transversion mutations. From the six singletons, five lead to transition mutations and one to a transversion mutation.

In the $800 \mathrm{bp}$ region of the $A B R E-B P$ promoter considered in the current study, the detected SNPs created and deleted cis-elements. Considering all 49 varieties, a total of 14 abiotic 
stresses related cis-elements were identified (Table 2; Fig. 2). Three of the cis-elements ACGTATERD1 (involved in expression of early response to dehydration), DPBFCOREDCDC3 (bZIP transcription factor binding sequence present in ABA inducible genes) and MYCCONSENSUSAT (present in dehydration responsive genes) were conserved across all 49 varieties. Based on the remaining $11 \mathrm{cis}$-acting elements related to abiotic stress responses that showed SNP variations, the 49 varieties were clustered in to nine groups at a similarity percentage cut -off of $68 \%$ (Fig. 3).

Table 2. Sequences of abiotic stress responsive cis-acting elements present in an $\mathbf{8 0 0}$ bp upstream region of the abscisic acid responsive element binding protein (Source: PLACE database)

\begin{tabular}{|c|c|c|}
\hline Cis-acting element & Sequence $\left(5^{\prime}-3^{\prime}\right)$ & Remarks \\
\hline ASF1MOTIFCAMV & TGACG & $\begin{array}{l}\text { Biotic and abiotic stress differentially } \\
\text { stimulate the activation sequence-1 } \\
\text { element (AS-1) (Després et al., 2003) }\end{array}$ \\
\hline MYCCONSENSUSAT & CATATG & $\begin{array}{l}\text { An MYC recognition site found in the } \\
\text { promoters of the dehydration responsive } \\
\text { gene }-r d 22 \text { and many other genes in } \\
\text { Arabidopsis (Abe et al., 1997) }\end{array}$ \\
\hline ACGTATERD1 & ACGT & $\begin{array}{l}\text { Required for the etiolation-induced } \\
\text { expression of erdl (early responsive to } \\
\text { dehydration) in Arabidopsis (Simpson et } \\
\text { al., 2003) }\end{array}$ \\
\hline DRE2COREZMRAB17 & ACCGAC & $\begin{array}{l}\text { DRE2 is found in ABA and drought } \\
\text { inducible genes (Kizis and Pages, 2002) }\end{array}$ \\
\hline DRECRTCOREAT & ACCGAC & $\begin{array}{l}\text { A dehydration responsive cis-acting } \\
\text { element (Yamaguchi-Shinozaki and } \\
\text { Shinozaki, 1994; Dubouzet et al., 2003) }\end{array}$ \\
\hline LTRECOREATCOR & CCGAC & $\begin{array}{l}\text { A low temperature stress responsive } \\
\text { element which related to ABA stress } \\
\text { response pathway. It contains the same } \\
\text { core sequence as DRE (Basu et al., 2014) }\end{array}$ \\
\hline CBFHV & CCGAC & $\begin{array}{l}\text { A C-repeat binding factor. Dehydration } \\
\text { responsive element (Nakashima et al., } \\
\text { 2009) }\end{array}$ \\
\hline MYBCORE & CCGGTTA & $\begin{array}{l}\text { Involved in water stress responses (Urao et } \\
\text { al., 1993) }\end{array}$ \\
\hline GT1GMSCAM4 & GAAAAA & $\begin{array}{l}\text { Salinity stress responsive element ( Park et } \\
\text { al., 2004) }\end{array}$ \\
\hline ACGTATERD1 & ACGT & $\begin{array}{l}\text { Element involved in the expression of early } \\
\text { response to dehydration (Simpson et al., } \\
2003 \text { ) }\end{array}$ \\
\hline DPBFCOREDCDC3 & ACACCTG & $\begin{array}{l}\text { bZIP transcription factor binding sequence } \\
\text { present in ABA inducing genes (Kim et al., } \\
\text { 1997) }\end{array}$ \\
\hline MYCCONSENSUSAT & CACCTG & $\begin{array}{l}\text { An MYC recognition site present in } \\
\text { dehydration responsive genes (Abe et al., } \\
\text { 1997) }\end{array}$ \\
\hline
\end{tabular}


Among the analyzed sequences there were two entries from the variety Hondarawalu (accessions IRGC 67631 and IRGC 47372). Accession level differences involving INDELs and SNPs were detected in the promoter region of Hondarawalu including, four INDELs and 14 SNPs. The variations detected among the Hondarawalu accessions indicated heterogeneity of the germplasm.

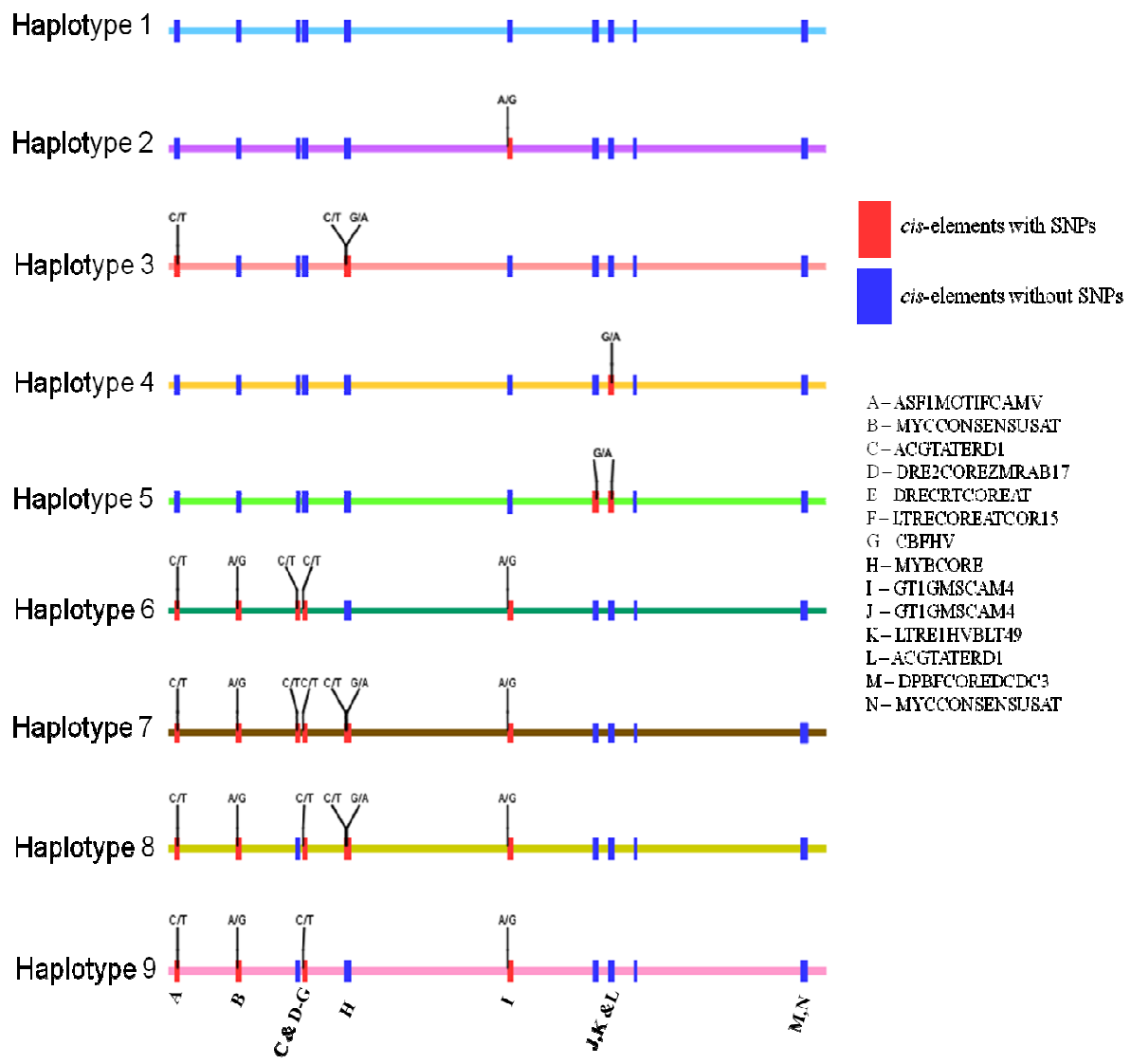

Fig. 2. Illustration of haplotypes based on abiotic stress related cis-elements and their single nucleotide polymorphisms in the promoter region of the abscisic acid responsive element binding protein among the selected Sri Lankan rice varieties 


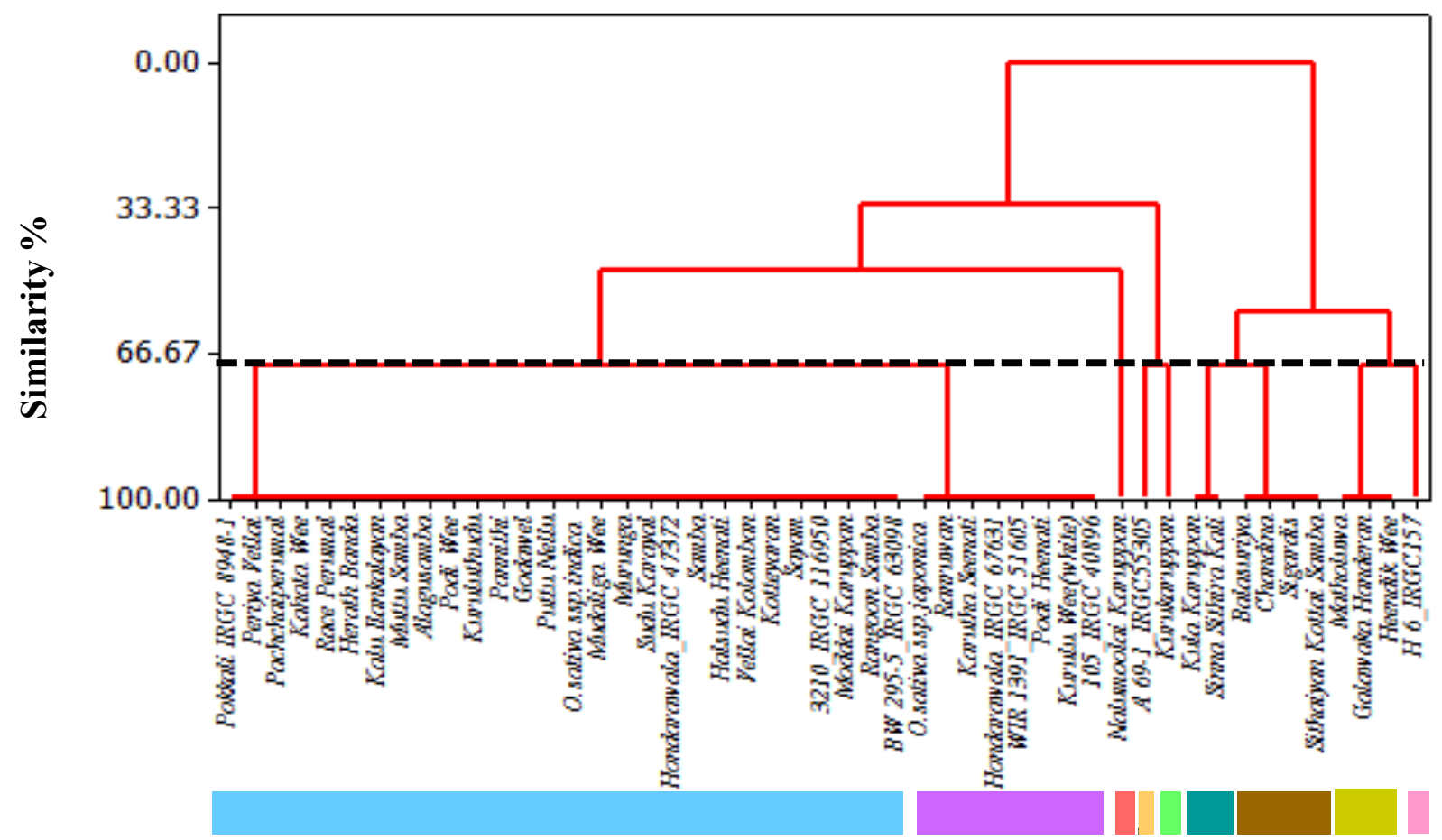

\section{Rice Varieties}
Haplotype 1
Haplotype 2
Haplotype 3
Hap lotype 4
Haplotype 5
Haplotype 6
Haplotype 7
Haplotype 8
Haplotype 9

Fig. 3. Cluster analysis of selected 49 rice varieties based on the single nucleotide polymorphisms in cis-elements of abscisic acid responsive element binding protein. Colored bars indicate the haplotype groups based on the clustering at a $68 \%$ similarity 
The tolerant variety Pokkali carried nine abiotic stress response related cis-elements and did not carry the stress responsive elements GT1GMSCAM4 (two copies found in other varieties) and the element LTRE1HVBLT49D found in other varieties. Further, five of the

identified abiotic-stress related elements in Pokkali (ACGTATERD1, DRE2COREZMRAB17, DRECRTCOREAT, LTRECOREATCOR15 and MYBCORE) were deleted in some other varieties.

Based on the current salinity ratings surveyed through available literature, the varieties Pokkali, Kuruluthuda, Kahata wee, and Kotteyaran has been reported as tolerant (de Costa et al., 2012; Pradheeban et al., 2014) and Nipponbare and Hondarawalu as susceptible (de Costa et al., 2012). The rating of Pachchaperumal remained ambiguous as de Costa et al., (2012) reported it as susceptible and Pradheeban et al., (2014) as tolerent at seedling stage. To our knowledge the remaining varieties were not evaluated for salinity responses.

\section{DISCUSSION}

Osmotic stress responses in plants controlled by different regulons involves a cascade of genes that get up-regulated and down-regulated based on environmental cues (Nakashima et al., 2009). The stress responses can get delivered via an ABA dependent or independent signal transduction pathway. These pathways involve specific cis-elements such as: dehydration responsive element (DRE), C- repeat (CRT), and ABRE that are responsible for regulating the expression of osmotic stress responsive genes. The DRE and CRT are known to be involved in both cold and drought stresses, while ABRE is mainly engaged with salinity and drought stress (Shinozaki and Yamaguchi-Shinozaki, 2000). Phytohormone ABA produced under osmotic stress is recognized by ABA receptors in the cell and the signaling components induce the ABA-dependent gene $A B R E-B P$ (Sairam and Tyagi, 2004). The $A B R E-B P$ codes for a bZIP family transcription factor which binds to the ABRE elements in the promoter of stress responsive genes up-regulating their expression (Chaves et al., 2003; Tuteja, 2007; Nakashima et al., 2014). The $A B R E-B P$ acts as an early responsive gene in ABA dependent stress responsive regulon (Sairam and Tyagi, 2004) and thus, the $A B R E-B P$ acts as a master regulator in ABA dependent stress response. The ciselements present, their relative distance and DNA polymorphisms involved in the promoter region could alter the expression of a gene (Dubouzet et al., 2003). Thus, such variations in the $A B R E-B P$ could alter its expression and affect the expression of the down-stream genes that are under its regulation. Hence, in the current study the diversity of cis-elements of $A B R E-B P$ were evaluated.

The analysis of the $A B R E-B P$ promoter sequences of 49 rice varieties retrieved from public databases showed several INDELs and SNPs. The sequence over the major INDEL (INDEL1- $25 \mathrm{bp}$ ) was found to be absent only in two varieties, PuttuNellu and cultivar 9311 (indica reference). However, the salinity ratings of PuttuNellu and cultivar 93-11 are not known. Among the varieties that have a sequence over the major INDEL, varieties such as Pokkali, Kuruluthudu, Kahata Wee and Kotteyaran were already reported as salinity tolerant and Hondarawalu as a susceptible variety (de Costa et al., 2012). Thus, the INDEL1 did not show a direct association to the currently reported salinity tolerance ratings. Similarly, none of the other INDELs and SNPs identified in the current study showed strong associations with available salinity ratings. Salinity is not under the control of a single gene; rather, it is controlled by several quantitative trait loci (QTL; Saltol (Mohammadi-Nejad et al., 2008; Thomson et al., 2010) and $q D W 1.1$ in chromosome 1, $q D W 2.1$ and $q D W 2.2$ in chromosome 
2, qDW6.1 in chromosome 6 (Bimpong et al., 2014), qSNC3 in chromosome 3, qSNC9 in chromosome 9 and $q S N C 11$ in chromosome 11 (Wang et al., 2012) and rab-16A (Mundy et al., 1990)). Thus, the overall salinity response is a cumulative effect of the responses coming from many QTL/genes. However, only the genes carrying the ABRE cis-elements are under the regulation of $A B R E-B P$. Only the promoter region of the gene rabl6A has been characterized to carry ABRE elements (Mundy et al., 1990). It is not known if the other QTL/genes responsible for salinity tolerance are carrying ABRE cis-elements or not.

Among various regulatory elements found in a promoter region, cis-elements play a key role in regulating gene transcription. The cis-elements get regulated by the status of various cellular responses, including signal molecules related to abiotic stresses (Chaves et al., 2003). The six INDEL sites detected in the current study did not fall over any cis-elements that were previously known to be associated with abiotic stress tolerance. However, an INDEL can cause a change in the relative positions of the adjacent cis-acting elements and thus could have an effect on the overall expression rate of the gene. Hence, it is recommended that an expression analysis be carried out for $A B R E-B P$ of different varieties to see if these INDELs have an effect on the relative expression of the gene. Out of the identified 11 abiotic stress responsive cis-elements, the elements MYBCORE (CNGGTTA) and GT1GMSCAM4 (GAAAAA) are known to be related to salinity stress responses. These cis-elements are present in the C3HC4-type RING finger gene family, which plays a key role in growth and development, and abiotic stress responses (Ma et al., 2009). The ciselement MYBCORE is also known to be involved in stress response regulation in rice plants under dehydration, salinity, drought and low temperature stress (Ma et al., 2009). Further, the cis-element GT1GMSCAM4 is also known to be related to salinity stress and biotic stress tolerance (Park et al., 2004; Ma et al., 2009; Trivedi et al., 2013). In stress responsive genes a GT-1 like transcription factor binds to the cis-element GT1GMSCAM4 and regulates responses under salinity stress (Park et al., 2004). Previous studies indicates the presence of GT1GMSCAM4 in most of the highly expressing genes in rice sperm cells (Sharma et al., 2011). The GT1GMSCAM4 element is found in known susceptible varieties such as Nipponbare and Honderawala and several other varieties with unknown salinity ratings, but not in known salinity tolerant varieties such as Pokkali (IRGC 8948-1), Kuruluthudu (IRGC 36304-1), Kahata Wee (IRGC 12004-1), Kotteyaran (IRGC 47383-1) and in several varieties with unknown salinity responses. Similarly a direct association could not be established with respect to the cis-element MYBCORE, due to lack of information related to salinity stress responses.

Based on the abiotic stress related cis-elements carrying SNP sites (11 sites; Fig. 2), the studied rice varieties were clustered into nine clusters (Fig. 3). The salinity tolerant variety Pokkali was clustered into haplotype 1 with tolerant varieties Kuruluthudu, Kahata Wee, Kotteyaran and moderately salinity tolerant variety Samba (de Costa et al., 2012; Pradheeban et al., 2014). However, within the same haplotype were the salinity susceptible variety Honderawala (de Costa et al., 2012), Pachchaperumal with an ambiguous salinity rank (de Costa et al., 2012; Pradheeban et al., 2014) and 20 other varieties of which the tolerance level is unknown. Thus, the SNPs in these elements are not strongly associated with salinity responses of these varieties.

Even though this in silico study revealed the nucleotide diversity of the cis-elements present in $A B R E-B P$ promoter region, the association of the detected polymorphisms to salinity tolerance ratings was not possible as the salinity responses of many of the tested varieties were not available. Therefore, it is recommended that a systematic phenotypic study be 
carried out to clearly identify the salinity rank of the used accessions at different life stages. The current study is an initial step to identify the nucleotide diversity of the cis-elements present in $A B R E-B P$ among a panel of Sri Lankan rice varieties, and based on the already available salinity ratings preliminary inferences were made on the associations of the DNA polymorphisms detected in the promoter region of $A B R E-B P$ with emphasis on salinity stress response related cis-elements.

\section{CONCLUSION}

The nucleotide diversity analysis of the $A B R E-B P$ promoter region revealed DNA polymorphisms among the studied rice varieties, and some of these polymorphisms were found within the cis-elements. A total of 11 cis-elements related to abiotic stress responses were detected and the identified SNPs deleted existed cis-elements or generated new ciselements. No INDELs fell on the cis-elements. The groups created based on a cluster analysis of these SNPs indicated that the SNPs in cis-elements of the ABRE-BP may not be a strong regulator of salinity tolerance. However, the INDELs changed the relative distance between cis-elements and their position from the TSS, imposing possible effects on the expression of the $A B R E-B P$ that regulate stress responsive genes enriched with ABRE element(s).

\section{REFERENCES}

Abe, H., Yamaguchi-Shinozaki, K., Urao, T., Iwasaki, T., Hosokawa, D. and Shinozaki, K. (1997). Role of Arabidopsis MYC and MYB homologs in drought and abscisic acid regulated gene expression. Plant Cell. 9, 1859 - 1868.

Bartels, D. and Sunkar, R. (2005). Drought and salt tolerance in plants. CRC. Crit. Rev. Plant Sci. 24, 23 - 58.

Basu, S., Roychoudhury, A. and Sengupta, D. N. (2014). Deciphering the role of various cisacting regulatory elements in controlling SamDC gene expression in rice. Plant Signal Behav. 9:e28391. [Online] Available at: http://dx.doi.org/10.4161/psb.28391. [Accessed $: 16 / 1 / 2017]$.

Bimpong, I.K., Manneh, B., El-Namaky, R., Diaw, F., Amoah, N.K.A., Sanneh, B., Ghislain, K., Abdulai, S., Singh, R. K., Gregorio, G., Bizimana, J. B. and Wopereis, M. (2014). Mapping QTLs related to salt tolerance in rice at the young seedling stage using 384-plex single nucleotide polymorphism (SNP), marker sets. Mol. Plant Breed. 5(9): 47-63. Chaves, M.M., Maroco, J.P. and Pereira, J.S. (2003). Understanding plant responses to drought from genes to the whole plant. Funct. Plant Biol. 30: 239 - 264.

De Costa, W.A.J.M., Wijeratne, M.A.D. and De Costa, D.M. (2012). Identification of Sri Lankan rice varieties having osmotic and ionic stress tolerance during the first phase of salinity stress. J. Natl. Sci. Found. Sri Lanka. 40(3), 251 - 280.

Després, C., Chubak, C., Rochon, A., Clark, R., Bethune, T., Desveaux, D. and Fobert, P. R. (2003). The Arabidopsis NPR1 disease resistance protein is a novel cofactor that confers 
redox regulation of DNA binding activity activity to the basic domain/ lucine zipper transcription factor TGA1. Plant Cell. 15, 2181 - 2191.

Dubouzet, J.G., Sakuma, Y., Ito, Y., Kasuga, M., Dubouzet, E.G., Miura, S., Seki, M., Shinozaki, K. and Yamaguchi-Shinozaki, K. (2003). OsDREB genes in rice, Oryza sativa L., encode transcription activators that function in drought, high salt and cold responsive gene expression. Plant J. 33(4), 751 - 763.

El-Swaify, S.A. (2000). Soil and Water Salinity. pp. 151-152. In: Silva, J.A. and Uchida, R. (ed.) Plant nutrition management in Hawaii's soils, approaches for tropical and subtropical agriculture. College of Tropical Agriculture and Human Recourses, University of Hawaii, Manoa.

Garcia, A.B., Engler, J.A., Claes, B., Villarroel, R., Van Montagu, M., Gerats, T. and Caplan, A. (1998). The expression of the salt responsive gene salT from rice is regulated by hormonal and developmental cues. Planta. 207, 172 - 180.

Higo, K., Ugawa, Y., Iwamoto, M. and Korenaga, T. (1999). Plant cis-acting regulatory DNA elements (PLACE) database:1999. Nucleic Acids Res. 27(1), 297 - 300.

Jain, M., Ghanashyam, C. and Bhattacharjee, A. (2010). Comprehensive expression analysis suggests overlapping and specific roles of rice Glutathione S-transferase genes during development and stress responses. BMC Genomics. 11: 73.

Kim, S.Y., Chung, H.J. and Thomas, L. (1997). Isolation of a novel class of bZIP transcription factors that interact with ABA-responsive and embryo-specification elements in the Dc3 promoter using a modified yeast one hybrid system. The Plant J. 11(6), 1237 1251.

Kizis, D. and Pages, M. (2002). Maize DRE-binding proteins DBF1 and DBF2 are involved in rab17 regulation through the drought-responsive element in ABA dependent pathway. The Plant J. 30(6), 679 - 689.

Ma, K., Xiao, J., Li, X., Zhang, Q. and Lian, X. (2009). Sequence and expression analysis of the C3HC4-type RING Finger gene family in rice. Gene. 444, 33 - 45.

Mohammadi-Nejad, G., Arzani, A., Rezai, A.M., Singh, R.K. and Gregorio, G.B. (2008). Assessment of rice genotypes for salt tolerance using microsatellite markers associated with the saltol QTL. Afr. J. Biotechnol. 7(6), 730 - 736

Mundy, J. and Chua, N. (1988). Abscisic acid and water stress induce the expression of a novel rice gene. EMBO J. 7(8), 2279 - 2285.

Mundy, J., Yamaguchi-Shinozaki, K. and Chua, N. (1990). Nuclear proteins bind conserved elements in the abscisic acid responsive promoter of a rice $r a b$ gene. Proc. Natl. Acad. Sci. U.S.A. 87(4), 1406 - 1410.

Nakashima, K., Ito, Y. and Yamaguchi-Shinozaki, K. (2009). Transcriptional regulatory networks in response to abiotic stresses in Arabidopsis and grasses. Plant Physiol. 149, 88 93. 
Nakashima, K., Yamaguchi-Shinozaki, K. and Shinozaki, K. (2014). The transcriptional regulatory network in the drought response and its crosstalk in abiotic stress responses including drought, cold, and heat. Front. Plant Sci. 5: 170.

Park, H.C., Kim, M.L., Kang, Y.H., Jeon, J.M., Yoo, J.H., Kim, M.C., Park, C, Y., Jeong, C.J., Moon B. C., Lee, J.H., Yoon, H.W., Lee, S., Chung, W.S., Lim, C.O., Lee, S.Y., Hong, J.C. and Cho, M.J. (2004). Pathogen and $\mathrm{NaCl}$ induced expression of the $S C a M-4$ promoter is mediated in part by a GT-1 Box that interacts with a GT-1-like transcription factor. Plant Physiol. 135(4), 2150 - 2161.

Pitman, M.G. and Lauchli, A. (2002). Global impact of salinity and agricultural ecosystems. pp.5. In: Lauchi, A. and Liittge, U. (ed.) Salinity: Environment- PlantsMolecules. Kluwer Academic Publishers, Netherlands.

Pradheeban, L., Nissanka, N.A.A.S.P. and Suriyagoda, L.D.B. (2014). Clustering of rice (Oryza sativa L.) varieties cultivated in Jaffna district of Sri Lanka based on salt tolerance during germination and seedling stages. Trop. Agric. Res. 25(3), 358 - 375.

Rabbani, M. A., Maruyama, K., Abe, H., Khan, M. A., Katsura, K., Ito, Y., Yoshiwara, K., Seki, M., Shinozaki, K. and Yamaguchi-Shinozaki, K. (2003). Monitoring expression profiles of rice genes under cold, drought, and high-salinity stresses and abscisic acid application using cDNA microarray and RNA gel-blot analyses. Plant Physiol. 133(4), 1755 $-1767$.

Sairam, R.K. and Tyagi, A. (2004). Physiology and molecular biology of salinity stress tolerance in plants. Curr. Sci. 86(3), 407 - 416.

Sankar, P.D., Saleh, M.A.A.M. and Selvaraj, C.I. (2011). Rice breeding for salt tolerance. Res. Biotechnol. 2(2), 1 - 10.

Sharma, N., Russell, S.D., Bhalla, P.L. and Singh, M.B. (2011). Putative cis-regulatory elements in genes highly expressed in rice sperm cells. BMC Res. Notes. 4: 319.

Shinozaki, K. and Yamaguchi-Shinozaki, K. (1997). Gene expression and signal transduction in water stress response. Plant Physiol. 115, 327 - 333.

Shinozaki, K. and Yamaguchi-Shinozaki, K. (2000). Molecular responses to dehydration and low temperature: differences and cross-talk between two stress signaling pathways. Curr. Opin. Plant Biol. 3, 217 - 223.

Simpson, S.D., Nakashima, K., Narusaka, Y., Seki, M., Shinozaki, K. and YamaguchiShinozaki, K. (2003). Two different novel cis-acting elements of erd1, a clpA homologous Arabidopsis gene function in induction by dehydration stress and dark-induced senescence. The Plant J. 33, 259 - 270.

Taji, T., Ohsumi, C., Iuchi, S., Seki, M., Kasuga, M., Kobayashi, M., Yamaguchi-Shinozaki, K. and Shinozaki, K. (2002). Important roles of drought- and cold-inducible genes for Galactinol Synthase in stress tolerance in Arabidopsis thaliana. Plant J. 29(4), 417 - 426. 
Thomson, M.J., De Ocampo, M., Egdane, J., Rahman, M.A., Sajise, A.G., Adorada, D., Tumimbang-Raiz, E., Blumwald, E., Seraj, Z. I., Singh, R. K., Gregorio, G. B. and Ismail, A. M. (2010). Characterizing the Saltol quantitative trait locus for salinity tolerance in rice. RICE. 3, 148 - 160.

Trivedi, D.K., Ansari, M.W. and Tuteja, N. (2013). Multiple abiotic stress responsive rice cyclophilin: (OsCYP-25) mediates a wide range of cellular responses. Commun. Integr. Biol. 6(5): e25260. [Online] Available at: http://dx.doi.org/10.4161/cib.25260. [Accessed: $16 / 1 / 2017]$.

Todaka, D., Shinozaki, K. and Yamaguchi-Shinozaki, K. (2015). Recent advances in the dissection of drought-stress regulatory networks and strategies for development of droughttolerant transgenic rice plants. Front. Plant Sci. 6: 84.

Tuteja, N. (2007). Abscisic acid and abiotic stress signaling. Plant Signal Behav. 2(3), 135 138.

Uno, Y., Furihata, T., Abe, H., Yoshida, R., Shinozaki, K. and Yamaguchi-Shinozaki, K. (2000). Arabidopsis basic leucine zipper transcription factors involved in an abscisic aciddependent signal transduction pathway under drought and high-salinity conditions. Proc.Natl. Acad. Sci. U.S.A. 97(21), 11632 - 11637.

Urao, T., Yamaguchi-Shinozaki, K. and Shinozaki, K. (1993). An Arabidopsis myb homolog is induced by dehydration stress and its gene product binds to the conserved MYB recognition sequence. Plant Cell. 5, 1529 - 1539.

Walia, H., Wilson, C., Condamine, P., Liu, X., Ismail, A. M., Zeng, L., Wanamaker, S.I., Mandal, J., Xu, J., Cui, X. and Close, T. J. (2005). Comparative transcriptional profiling of two contrasting rice genotypes under salinity stress during the vegetative growth stage. Plant Physiol. 139(2), 822 - 835.

Wang, Z., Chen, Z., Cheng, J., Lai, Y., Wang, J., Bao, Y., Huang, J. and Zhang, H. (2012). QTL analysis of $\mathrm{Na}^{+}$and $\mathrm{K}^{+}$concentrations in roots and shoots under different levels of $\mathrm{NaCl}$ stress in rice (Oryza sativa L.). PLoS ONE. 7(12): e51202.

Yamaguchi-Shinozaki, K. and Shinozaki, K. (1994). A novel cis-acting element in an Arabidopsis gene is involved in responsiveness to drought, low-temperature or high-salt stress. Plant Cell. 6, 251 - 264. 